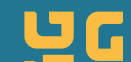

\section{O Encontro Etnográfico em Do Outro Lado do Atlântico}

\author{
The Ethnographic Meeting in From The Other Side of the Atlantic
}

\section{DANIELE ELLERY MOURÃO}

Universidade da Integração

Internacional da Lusofonia Afro-

Brasileira (UNILAB)

Antropóloga e realizadora é doutora em Ciências Sociais pelo PPCIS/ UERJ (2013) e mestra em Sociologia pelo PPGS/UFC (2006).

É professora efetiva do Bacharelado em Humanidades e do Curso de Licenciatura em Sociologia, no Instituto de Humanidades (IH/ UNILAB-CE). É líder do grupo de pesquisa: "SENSORIA - Núcleo de Pesquisa em Imagem, Som e Texto" (Unilab) e integra o "Todas as Artes - Todos os Nomes. Pesquisas sobre Arte na Contemporaneidade" (UFF). https://orcid.org/0000-00016226-9943

ellerymourao@gmail.com

\section{MÁRCIO ELÍSIO CARNEIRO CÂMARA}

Cineasta e Técnico de Som

Direto é professor titular do curso de Cinema e Audiovisual da Universidade de Fortaleza (UNIFOR).

Doutorando (PPGCOM/UFPE),

Mestre em Comunicação (UFF)

e Bacharel em Cinema pela San Francisco State University (SFSU). https://orcid.org/0000-00015799-9781

euphemiafilmes@gmail.com

\section{RESUMO}

O ensaio visual pretende discutir o processo de realização do documentário Do Outro Lado do Atlântico, com estudantes de Países Africanos de Língua Oficial Portuguesa (PALOP) no Brasil, a partir da ideia de um "encontro etnográfico". Traz uma reflexão sobre a abordagem dos "documentários de busca", e seus processos de subjetivação, ao mesmo tempo que busca reafirmar uma postura contra-colonial e antirracista, desconstruindo imaginários visuais de raça, subalternidade e estereótipos de África.

Palavras-chaves: Documentário, contra-colonial, imaginários visuais

\begin{abstract}
The visual essay aims to discuss the process of making the documentary The Other Side of the Atlantic, with students from Portuguese-speaking African Countries (PALOP) in Brazil, from the idea of an "ethnographic meeting". It brings a reflection on the approach of "search documentaries", and their processes of subjectivation, while seeking to reaffirm a counter-colonial and antirracist posture, deconstructing visual imaginaries of race, subalternity and stereotypes of Africa.
\end{abstract}

Keywords: Documentary, countercolonial, visual imaginary 


\section{TRAJETÓRIAS E MOTIVAÇÕES}

Após mais de 10 anos de pesquisas sobre os fluxos internacionais de estudantes de Países

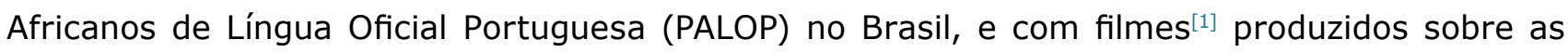
reconfigurações identitárias no contexto da diáspora, eu e Márcio Câmara decidimos nos lançar na produção de um longa-metragem sobre o tema. O nosso profundo envolvimento com o campo, desde 2002, nos possibilitou imaginar a feitura de um filme que expressasse a potência de um "encontro etnográfico" entre nós e os interlocutores no documentário. Assim, nasceu Do Outro Lado do Atlântico (90min. 2016) ${ }^{[2]}$.

Eu mais voltada à pesquisa etnográfica com estudantes dos PALOP no Brasil, Cabo Verde, Guiné-Bissau e Portugal, e o Márcio trazendo o know-how de uma formação em Cinema e larga experiência em sets de filmagens com Som Direto, nos aventuramos em busca das diversas Áfricas no Brasil. E por que não dizer também em busca de nós mesmos, dos nossos processos subjetivos inseridos em contextos de construção de imaginários e desconstruções imagéticas de raça, subalternidade e estereótipos de África.

As interpelações em torno da questão étnico-racial, da branquitude, o contexto local em que nos inserimos (eu, especialmente, na Unilab) e nossas experiências como pessoas que um dia também migraram, vivendo em lugares outros que não os de origem, motivaram a artesania do documentário.

Nos instigava falar da questão racial no processo fílmico, uma vez que os estudantes dos PALOP eram identificados pelos brasileiros como "negros, estrangeiros e africanos", de forma homogênea, sem considerar a diferenciação cultural e nacional entre os seus países de origem, como se a própria África fosse um país. Como pesquisadores e realizadores brancos no Brasil, um país tão desigual que mantém diversos privilégios para as pessoas brancas e variadas formas de opressões para pessoas negras, uma busca de nós mesmos nesse encontro questionava uma tomada de posição. Qual o nosso "lugar" dentro do filme no diálogo com as pessoas na tentativa de produzir uma obra antagônica à supremacia da "branquitude" e à construção de estereótipos de subalternidade sobre o continente africano e os/as estudantes dos PALOP?

Partimos da premissa do encontro e de uma escuta atenta, seguindo os caminhos da vietnamita-americana Trinh T. Minh-ha e as mudanças no campo dos filmes etnográficos, em que a diretora, além de criadora, é personagem em seu próprio filme. Bill Nichols (2005, p. 163) apud Rafael Coelho (2012, p. 763) destacou que em Reagrupamento (1982), ao declarar que "vai falar 'próxima' da África, em vez de falar 'sobre a África'", a diretora marca uma ruptura com o "olhar fixo da câmera de representar, ou descrever enganosamente, os outros". Também com inspiração na obra de Eduardo Coutinho, buscamos o hibridismo no filme optando por entrevistas em formato 
de longas conversas, aliadas à algumas cenas que planejamos e ensaiamos, juntamente com os estudantes, e outras não planejadas, complexificando a ideia da verdade no documentário como algo que deveria transmitir uma informação "naturalmente verdadeira". (FROCHTENGARTEN, 2009; NICHOLS, 2005).

O ensaio pretende, então, expressar o processo de realização e a potência desse encontro etnográfico por meio de trechos do filme Do Outro Lado do Atlântico que anunciam uma abordagem dos "documentários de busca", em que a subjetividade dos diretores se faz presente (LINS, 2007), ao mesmo tempo que reafirma uma postura contra-colonial e antirracista.

O primeiro vídeo ${ }^{[3]}$ contextualiza o campo, enquanto anseia lançar um "olhar decolonial" ao confundir/borrar/misturar imagens e sons. Ao escolhermos não dizer (com legendas) onde estamos criamos espelhamentos na construção de imaginários dos dois lados do Atlântico desconstruindo ideias pré-estabelecidas de uma África pobre e rural.

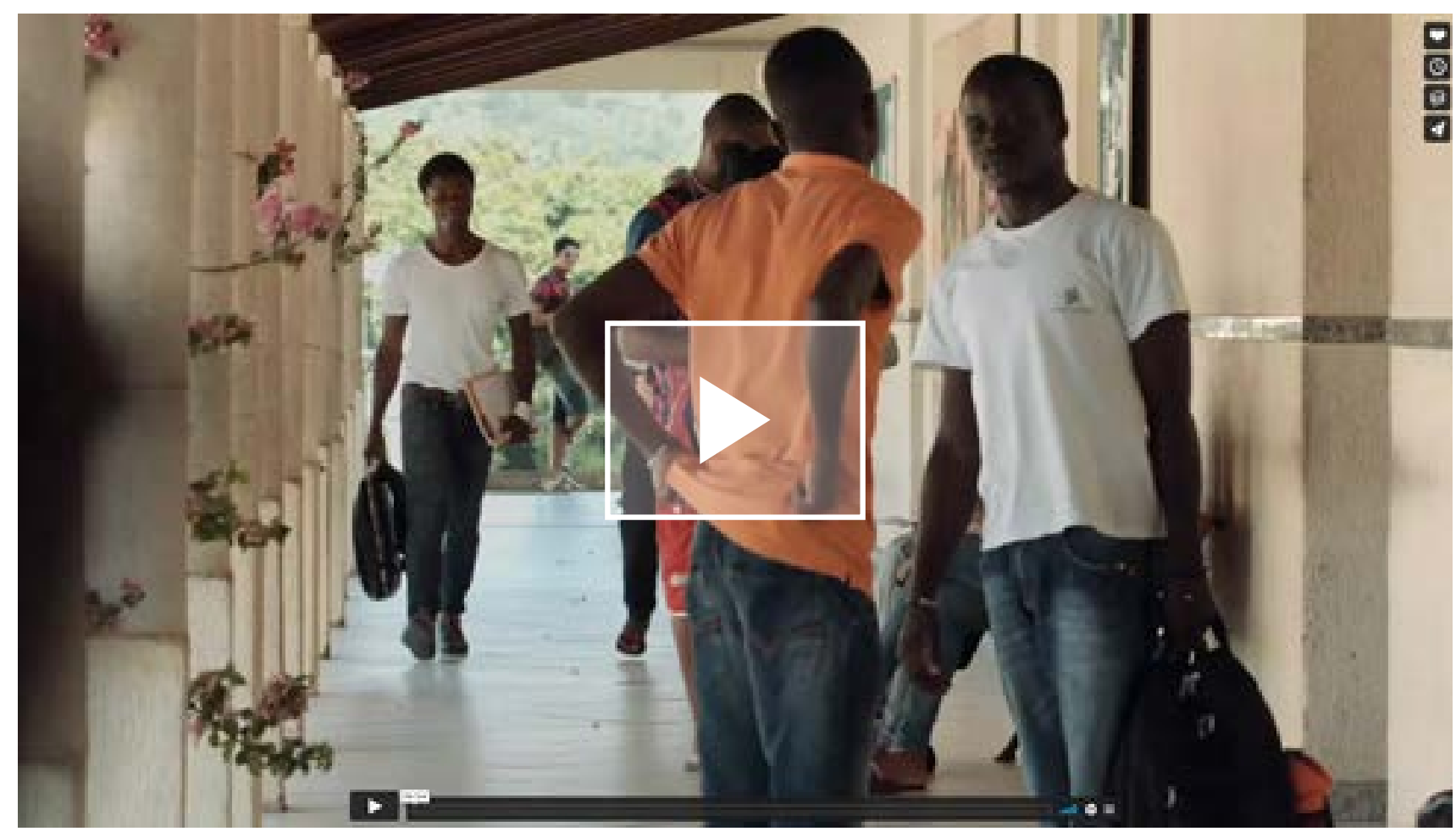

FIGURA 1: Do Outro Lado do Atlântico / Vídeo 1 DOLA_ALTA_1 on Vimeo 


\section{O CAMPO - TENSÕES E INTERPELAÇÕES}

A vinda de estudantes do continente africano para o ensino superior no Brasil não é uma novidade. Os Programas de convênio estudantil PEC-G e PEC-PG existem desde os anos 1965 e 1981, fazendo dos estudantes de África (e de outros continentes) beneficiários dessas ações conduzidas pela política externa brasileira. A criação da Universidade da Integração Internacional da Lusofonia Afro-brasileira (Unilab) e da Universidade Federal da Integração Latino-Americana (Unila), em 2010, ocorre na esteira dessas relações de cooperação já existentes, ainda que aprofundadas por uma nova política externa de fortalecimento das relações SUL-SUL.

Entretanto, o caso da Unilab, construída para receber estudantes dos PALOP, permitiu ampliar as condições de acesso ao ensino superior para pessoas de diferentes classes sociais e regiões desses países, e não apenas para as elites nacionais, como era mais comum anteriormente. Além disso, a criação da universidade reafirmou a importância dada à formação superior como um elo da cooperação entre países que tiveram no passado o mesmo colonizador, incrementando o campo das relações políticas, econômicas e culturais com a África, sobretudo no âmbito da Comunidade dos Países de Língua Portuguesa (CPLP).

O fluxo de estudantes de países africanos no Brasil tem possibilitado diversas reflexões sobre a questão étnico-racial, especialmente, na medida em que eles passam a viver em um país estruturalmente negro e mestiço, mas que teima em não reconhecer sua negritude. Como vemos em Do Outro Lado do Atlântico, as relações sociais decorrentes do processo de trânsito para as universidades brasileiras ativam tensões raciais e identitárias a partir da ideia de um encontro, que ora constrói diferenças e conflitos, ora trocas culturais, afetivas e aprendizados mútuos (MOURÃO \& ABRANTES, 2020).

Um filme que observa a construção das relações étnico-raciais entre guineenses, angolanos, cabo-verdianos, moçambicanos, são-tomenses e brasileiros, em contexto diaspórico e contemporâneo (com a Unilab como pano de fundo), permite produzir conhecimentos sobre diversos silenciamentos históricos próprios da retórica do colonialismo moderno. Um processo que, na perspectiva de Quijano (2000, p. 342), carrega a ideia da colonialidade como "um dos elementos constitutivos e específicos do padrão mundial de poder capitalista". Como também abordado por Mignolo (2017. p. 2), trata-se de um conceito que "[...] nomeia a lógica subjacente da fundação e do desdobramento da civilização ocidental desde o Renascimento até hoje [...]", como um projeto histórico, econômico e político produtor de relações hierarquizantes de poder que criam e recriam desigualdades e racismos estruturais corporificados em imagens de inferioridade do "negro" e superioridade do "branco".

Nesse sentido, de uma ruptura com a colonialidade (suas estruturas de dominação e distribuição desigual de privilégios), o diálogo com os interlocutores possibilitou falar sobre 
construção de identidades e diferenças, e das desigualdades raciais no Brasil, as quais os estudantes não imaginavam encontrar em suas cidades de destino, cada lugar com suas particularidades em recriar formas de exclusão e inferiorização das pessoas negras. A situação ainda se exacerba com o racismo cultural e nacional, além do biológico, que carrega suas tintas na construção da xenofobia trazendo à tona antigos e novos conflitos.

E o que significava para nós, pessoas brancas e privilegiadas, problematizar as relações raciais e de poder em um filme etnográfico? A experiência da "observação participante", na antropologia, nos ofereceu pistas para responder essas questões. Jean Rouch foi responsável por um giro paradigmático na antropologia visual ao trazer em suas obras uma presença do diretor assumidamente reflexiva, definindo-a como "antropologia partilhada". Ao falar como o filme etnográfico podia ajudar a "partilhar" a antropologia, Rouch (2011, p. 79-80) observou que além das mudanças tecnológicas na captura de sons e imagens, o que o amanhã nos reservava era:

\footnotetext{
[...] uma câmara tão 'participante' que passará automaticamente para as mãos dos que, até aqui estavam à frente dela. Então o antropólogo não mais terá o monopólio da observação, será ele próprio observado, registrado, ele e a sua cultura. (ROUCH, 2011, p. 80).
}

Em nosso processo, esse compromisso com a restituição e a reflexividade, invertendo lógicas de poder, também deveria estar engajado com as interpelações aos privilégios da branquitude, investindo em um "lugar de fala" não apenas compartilhado e restituído, mas que supusesse aquilo que Lourenço Cardoso (2010) denominou de "branquitude crítica". Ao observar os conflitos enfrentados por pessoas brancas antirracistas por se reconhecerem fazer parte do grupo opressor, Cardoso (2010, p. 624) mostra-nos que uma das primeiras tarefas seria "uma dedicação individual cotidiana e, depois, a insistência na crítica e autocrítica quanto aos privilégios do próprio grupo".

\section{ESTRATÉGIAS AFETIVAS DE ABORDAGEM}

Por meio de uma busca por nós mesmos, com um olhar aguçado sobre nossas próprias construções identitárias e imagéticas sobre África, negociadas na relação com os interlocutores, a estratégia de atuar como personagem, como figurado no segundo vídeo ${ }^{[4]}$, intencionava quebrar com a posição de autoridade do/a diretor/a como único/a detentor/a do conhecimento. 


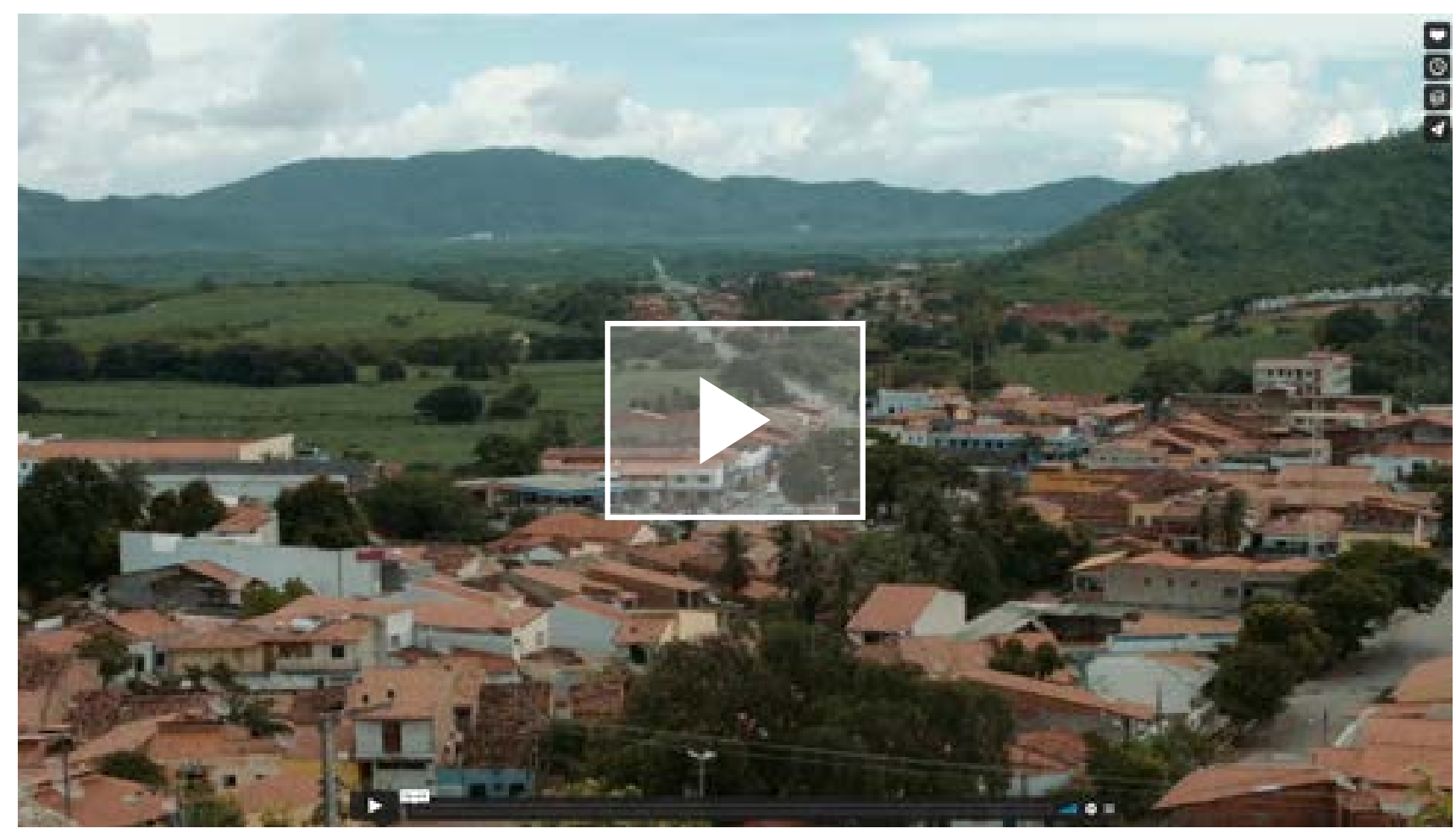

FIGURA 2: Do Outro Lado do Atlântico / Vídeo 2 DOLA_ALTA_2 on Vimeo

Investimos em epistemologias que priorizaram a heteroglossia, ao considerar as diversas vozes sociais na compreensão do dialogismo dos diferentes discursos como potência coletiva na produção de imagens e sons. Ao invés de falar por sobre os ombros de nossos/as interlocutores/as, desenhamos uma figuração imagética e sonora voltada para o "falar com". Ou, como propôs James Clifford (2008), acerca da "antropologia negociada", com um comprometimento com a interação no campo de pesquisa no sentido de minimizar as assimetrias. É a partir de um olhar que transcende as lógicas hierárquicas, da clássica relação entre observador e observado, que Do Outro Lado do Atlântico anseia ganhar outra dimensão: "Quem filma (observador) e quem está sendo filmado (observado) constroem e investigam juntos e ao mesmo tempo" (COELHO, 2012, p. 758).

Assim, o nosso movimento reflexivo, ainda que com a participação da diretora/personagem sem voz off ou narração subjetiva/explicativa sobre sua presença - em busca de si mesma nesse encontro de mais de 15 anos de idas e vindas a Cabo Verde e Guiné-Bissau -, procurou performar o compartilhamento de experiências e afetividades com os/as interlocutores/as, como figurado

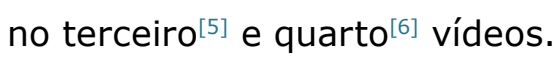




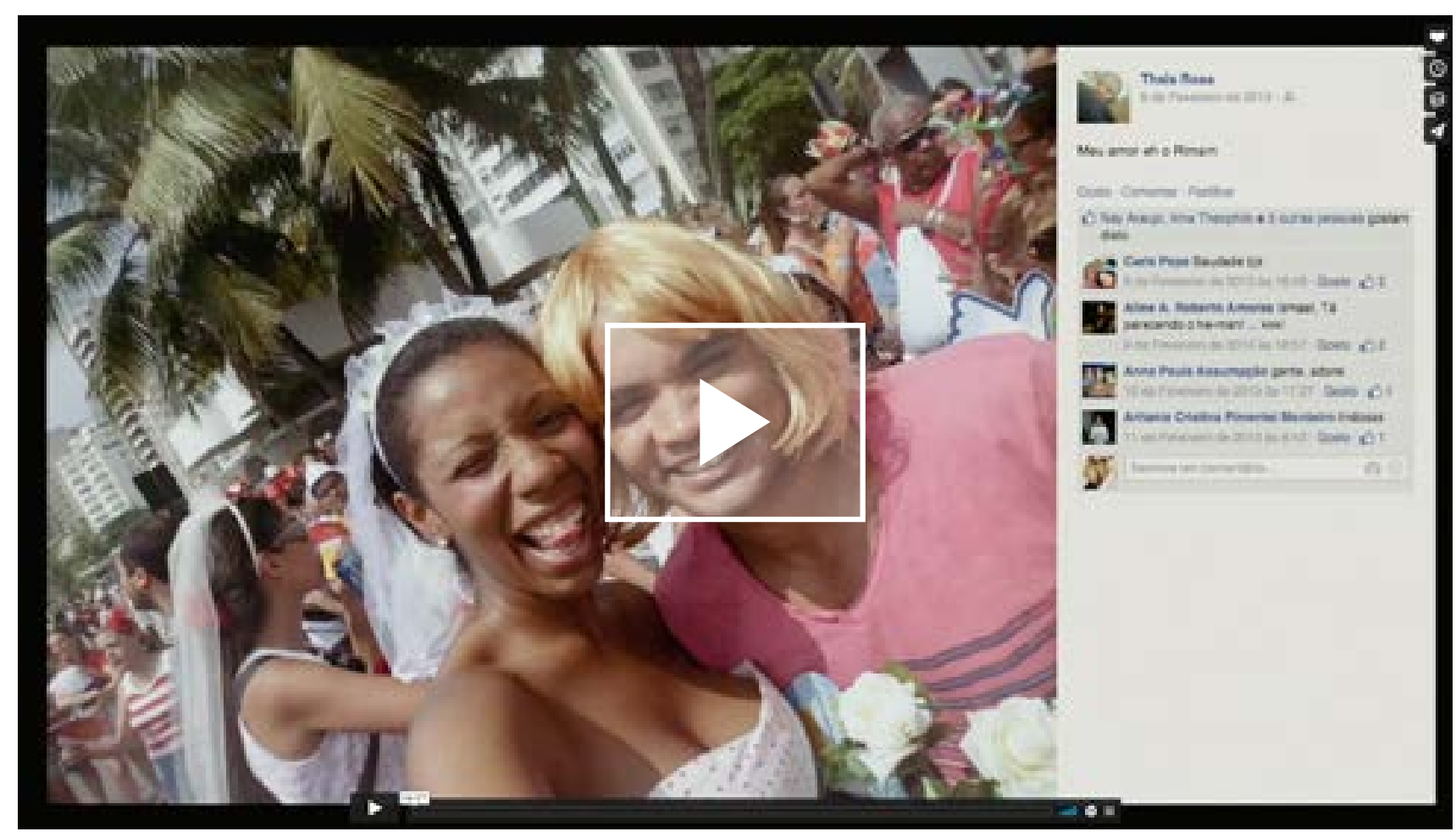

FIGURA 3: Do Outro Lado do Atlântico / Vídeo 3 DOLA_ALTA_3 on Vimeo

O motivo dessa abordagem subjetiva mais discreta foi pela sensação de que o filme não era especificamente sobre os diretores (sobre mim, nós), mesmo sendo também sobre nós. Pois, ao filmar e atuar nele, assumimos que estamos vivenciando sensações junto com os/as personagens, negociando temas, planos, conflitos, afetos e a nossa relação de proximidade com as pessoas, algumas delas grandes amigas. Por fim, destacamos que a recepção e apropriação do filme, com o reconhecimento de prêmios nacionais e internacionais, têm contribuído para múltiplos debates sobre a relação ambígua da sociedade brasileira com suas populações negras (do Brasil ou de além-mar), olhando para a produção de conhecimento em filme etnográfico de modo a subverter as lógicas de poder entre sujeitos e objetos do conhecimento. 


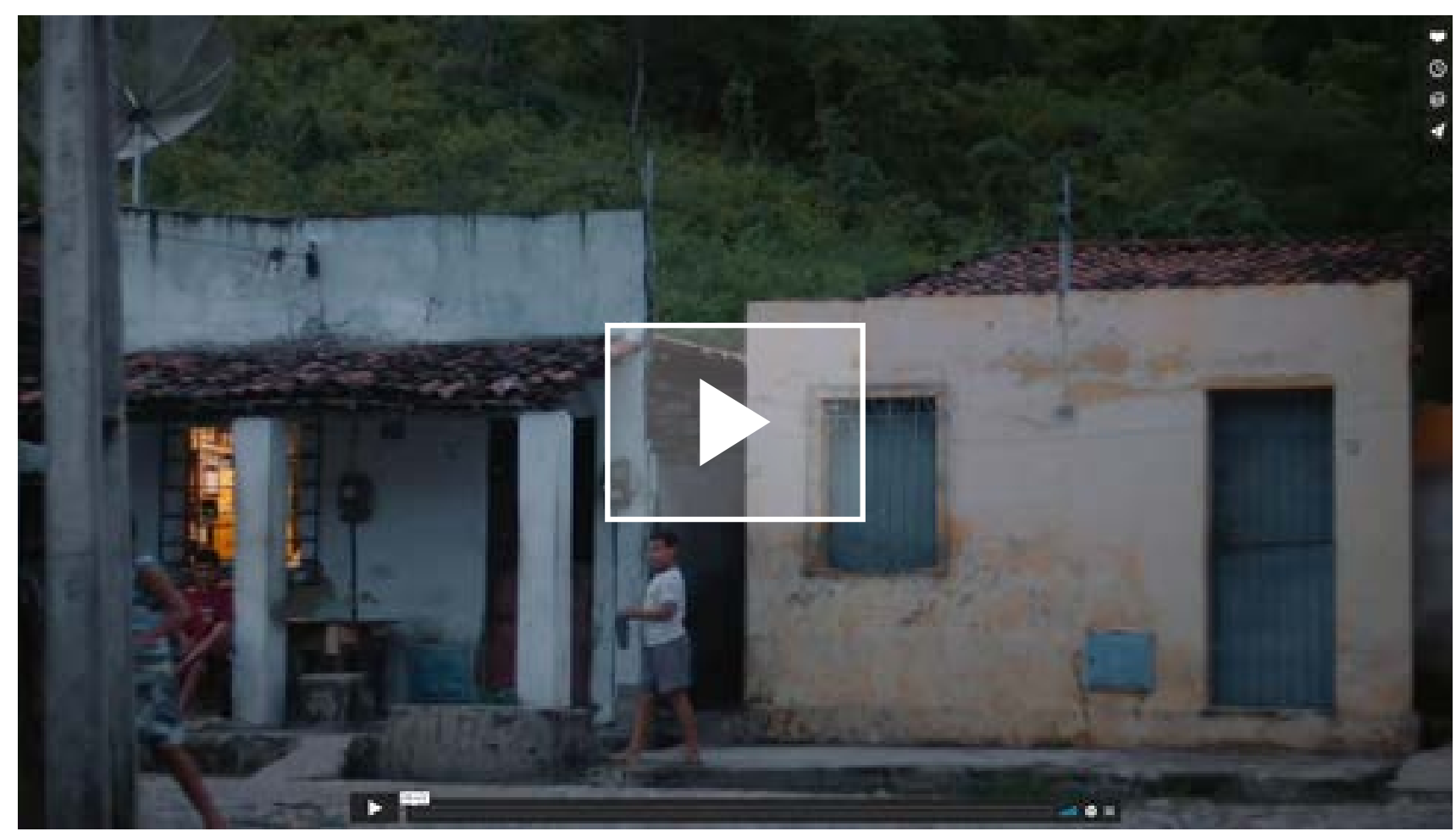

FIGURA 4: Do Outro Lado do Atlântico / Vídeo 4 DOLA_ALTA_4.mp4 on Vimeo

\section{REFERÊNCIAS}

MOURÃO, Daniele Ellery; ABRANTES, Carla Susana Além. Estudantes Africanos dos PALOP em Redenção, Ceará, Brasil: Representaģões, Identidades e Poder. 66. MEDIAÇÕES, Londrina, v. 25, n. 1, p. 64-81, jan-abr. 2020.

CARDOSO, Lourenço. Branquitude: estudos sobre a identidade branca no Brasil. Curitiba: Appris Editora, 2018.

CLIFFORD, James. Sobre a autoridade etnográfica. In: CLIFFORD, James. A experiência etnográfica: antropologia e literatura no século XX. 3. ed. Rio de Janeiro: UFRJ, 2008.

COELHO, Rafael Franco. Algumas notas sobre a bistória do cinema documentário etnográfico. Revista Comunicación, Piura, v. 1 , n. 10 , p. $755-766,2012$.

FROCHTENGARTEN, Fernando. A entrevista como método: uma conversa com Eduardo Coutinho, Psicologia USP [online], São Paulo, vol.20, n.1, p. 125-138, jan-mar. 2009. 
LINS, Consuelo. O ensaio no documentário e a questão da narração em off. In: FILHO, João Freire; HERSCHMANN, Micael (Orgs.). Novos rumos da cultura da mídia: indústrias, produtos, audiências. Rio de Janeiro: Mauad, 2007, pp. 143-157.

MIGNOLO, Walter. Colonialidade: o lado mais escuro da modernidade. Revista Brasileira de Ciências Sociais. v. 32 n. 94 , jun. 2017.

NICHOLS, Bill. Introdução ao documentário. Campinas: Papirus, 2005.

QUIJANO, Aníbal. Colonialidaddel poder y clasificación social. In: S. Castro-Gómez \& R. Grosfoguel (Orgs.). El giro decolonial: reflexiones para una diversidad epistémica más allá del capitalismo global. Bogotá: Siglo del Hombre Editores. Universidad Central, Instituto de Estudios Sociales Contemporáneos y Pontificia Universidad Javeriana, 2007.

ROUCH, Jean. A Câmara e os Homens. In: José Manuel Costa \& Luís Miguel Oliveira (Orgs). Jean Rouch. Cinemateca Portuguesa-Museu do Cinema, Festival Internacional de Cinema DocLisboa. - Lisboa: C.P.-M.C., p. 61-80, 2011.

[1] Identidades em Trânsito (2007) - https://vimeo.com/114765418; Partir, Permanecer, Regressar (2018) - https://www. youtube.com/watch?v=1TRUJoQJe0c

[2] Filme completo (legendas inglês) - https://drive.google.com/file/d/1E-fLgafOiCGBGN26DThG1s0WQWKEVg9m/ view? $\mathrm{usp}=$ sharing

[3] Vídeo 1 - https://vimeo.com/467959783

[4] Vídeo 2 - https://vimeo.com/469021595

[5] Vídeo 3 - https://vimeo.com/470178413

[6] Vídeo 4 - https://vimeo.com/467419830 